\title{
Obituaries
}

\author{
Editor: Henry R. Rollin
}

\section{VASSILIS NichOLAS MiNaS, formerly Consultant Psychiatrist, Basildon and Runwell Hospitals, Essex}

Vassilis Minas died at home in Greece on 7 December 1992. He was appointed consultant in General Adult Psychiatry at Basildon in January 1991 and thrust himself into the post with vigour and urbane bonhomie. A year into his post he developed some apparently trivial symptoms, but within a few weeks it was evident that he had widespread myelomatosis which, despite major effort at St Bartholomews Oncology Unit, proved resistant to treatment.

Minas was born in 1941 in Serres, Greece, and was an only child. He studied medicine at the University of Thessaloniki. There he helped to organise the University Radio Station and to found the University Theatrical Company where he directed plays with some acclaim. He qualified in 1969, and after two years compulsory military service did one year of general practice in Greece, one year of general medicine in Northern Italy, and then as planned, came to the UK to study psychiatry.

On arrival in 1973, he was appointed a clinical assistant at Claybury and later served as SHO at Stanley Road and Wexham Park Hospitals and subsequently served at St Francis Hospital Haywards Heath, Shenley, St Ann's and the North Middlesex hospitals. He had planned to return to Greece, but in the early 1980s decided to stay here and he obtained his MRCPsych in 1984. His further training took place at Goodmayes and Runwell \& Rochford hospitals. En route, he took a course at the Tavistock Clinic and kept an interest in psychotherapy, transcultural psychiatry and liaison work.

The latter interests reveal his breadth and range of skills. He read and spoke several languages fluently, kept up his interest in theatre, read widely on history and literature and travelled afar. He could, and did, contribute to many a discourse except concerning television which he excluded from his home. Despite the outward prolific flow of ideas and observations few knew the inner man. Friends were somehow compartmentalised.

He was unmarried and he is survived by his octogenarian mother and a second cousin who is currently pursuing medical studies in the UK.

A. C. Kaeser

\section{Erix Strómgren, Emeritus Professor, Univensity of Aarhus, Denmark}

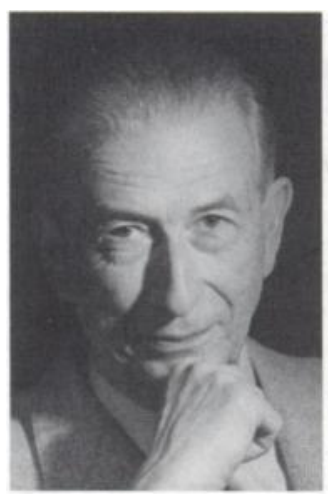

Erik Strömgren, who died on 15 March 1993, was the worldwide doyen of psychiatric epidemiology. His only rival for this role was Paul Lemkau, whose death had occurred only a few months earlier. Born in Copenhagen in 1909 , Strömgren graduated in medicine from the University of Copenhagen in 1934, and took his habilitation as Doctor in 1939. His psychiatric training was primarily at the University Hospital in Copenhagen, but in 1943 he moved to the University of Aarhus as Lecturer in Psychiatry, with the task of beginning systematic psychiatric teaching in the medical school. In 1945, he was appointed Professor there, and at the same time Medical Superintendent of the psychiatric hospital. His interest in genetics was acknowledged the following year with the additional title of Lecturer in Human Genetics.

During the 1950s and '60s, Professor Strömgren was responsible for the gradual evolution of the mental hospital into a comprehensive institute for treatment, training, and research. As a result, it was designated a WHO Collaborating Centre for Research \& Training. Soon after his arrival in Aarhus, he began epidemiological studies on the island of Samso, and remained actively involved in these for over 50 years. (The only comparable project to this is also in Scandinavia - at Lundby in southern Sweden, where Professor Essen-Möller showed similar longevity). The methods developed in the Samso work were of fundamental importance in the development of psychiatric epidemiology.

Aarhus was also a Field Research Centre for the WHO International Pilot Study of Schizophrenia, from 1965. In addition to his epidemiological interests, Professor Strömgren was chairman for some years of the WPA Section on Nomenclature \& Classification. He became an editor of Acta Psychiatrica Scandinavica in 1953, wrote the standard Danish textbook of psychiatry, and was the author of innumerable publications. 
In Denmark, he played an indispensable part in the planning and organisation of mental health services, and was also Adviser to the German Federal Ministry of Research \& Technology. The honours he received included an Honorary Doctorate of the University of Rochester, the Kraepelin and WagnerJauregg Medals, Honorary Fellowship of the Royal College of Psychiatrists, Corresponding Fellowship of the American Psychiatric Association, and similar recognition in Denmark, Switzerland, Finland, France, Sweden and Germany. He continued work- ing up to the end, and continued to make wise and learned contributions to his subject.

Personally, Erik Strömgren was shy and reserved, but marked by an unfailing old-world courtesy; those who had the chance to know him better bear witness to his kind and generous nature. He was punctilious in fulfilling responsibilities and could be relied on to complete any commitment to the highest standard. His wife was also a psychiatrist, and they had three children.

Hugh Freeman

\section{Family Work for Schizophrenia A Practical Guide}

\section{By LIZ KUIPERS, JULIAN LEFF and DOMINIC LAM}

This is a detailed manual of instructions for family work, written by three authors who have developed a course for teaching their approach to working with families of schizophrenic patients. Practical issues are outlined, such as engaging the family, treading the fine line between therapist and guest in the family's home, and teaching the family a problem-solving approach. Dealing with the relatives' emotional responses, the various approaches for different types of household, and cultural issues are also covered.

Price $£ 10.00,128 p p .$, ISBN 0902241494

GASKELL 